\title{
Rancang Bangun Turbin Crossflow Pancaran Ganda Kapasitas 5-100 KW
}

\author{
Abdul Salam ${ }^{*}$, Luther Sonda ${ }^{2}$, Jeremiah Ritto $^{3}$, Andi Muh. Rizqy ${ }^{4}$, Yobinsa Titting ${ }^{5}$ dan \\ Supriandi Tarru' Padang ${ }^{6}$ \\ 1,2,3,4,5,6 Jurusan Teknik Mesin, Politeknik Negeri Ujung Pandang, Makassar 90245, Indonesia \\ *abd_salam@poliupg.ac.id.com
}

\begin{abstract}
Build Design of Double Jet Cross-flow Turbine With 5-100 kW Capacity is purposes know time and turbine manufacturing charge with low turbine dimension and also to know the rotation of turbine's pivot runner. The basic of this design with literature study, planning design, and preparation of tools and materials, build the turbine, calculation of the time and charge, discussion, and the conclusion. And Obtainable of the time result to build turbine's machine is 33 hours and 55 minutes, from the calculation charge of the machine the result is Rp.15.661.863, and the profit achievement BEP reached when the sale of turbine as much as 3 turbine's in a month or when the income reach Rp.27.412.022.
\end{abstract}

Keywords: Cross-flow turbine, pivot, manufacturing charge, BEP.

\begin{abstract}
Abstrak: Rancang bangun turbin crossflow pancaran ganda kapasitas 5-100 kW, bertujuan untuk mengetahui waktu serta biaya manufaktur turbin dengan dimensi turbin yang lebih ramping dan juga untuk mengetahui putaran pada poros runner turbin. Dasar perancangan dilakukan dengan studi literatur, desain perancangan, persiapan alat dan bahan, rancang bangun turbin, penghitungan waktu serta biaya pembuatan, pembahasan, dan pembuatan kesimpulan. Hasil yang diperoleh dalam perancangan untuk total waktu pemesinan turbin adalah 33 jam 55 menit, dari penghitungan pemesinan didapatkan biaya manufaktur turbin yaitu sebesar Rp 15.661.863,dan pencapaian kondisi BEP tercapai saat penjualan turbin sebanyak 3 unit dalam satu bulan atau pada saat penghasilan mencapai Rp27.412.022.
\end{abstract}

Kata kunci : turbin crossflow, poros, waktu, biaya manufaktur, BEP.

\section{PENDAHULUAN}

Potensi energi air di Indonesia memiliki sangat besar, telah banyak dimanfatkan untuk pembangunaqn PLTA dan sebagian telah dimanfaatkan utamanya energi air skala kecil untuk memenuhi kebutuhan energi listrik masyarakat pedesaan [1]. Energi air skala kecil yang dimanfaatkan adalah berupa PLTMH, pembangunan PLTMH telah banyak dilakukan [2]. Pembangunan PLTMH pada daerah belum terjangkaub PLN utamanya pedesaan dengan penduduk sedikit merupakan pilihan tepat karena PLTMH memiliki banyak kelebihan [2].

Penelitian tentang PLTMH telah banyak dilakukan diantaranya penelitian kinerja turbin crossflow akibat pengaruh jumlah sudu diperoleh effisiensi 22,3\% [3], penelitian kinerja turbin cross flow akibat pengaruh posisi sudu pengarah diperoleh effisiensi 13,48\% [4], penelitian karakteristik aliran dan kinerja turbin crossflow akibat pengaruh perubahan nozzle dan sudu turbin [5-6] diperoleh effisiensi $74,88 \%$ [6]. Juga telah dilakukan penelitian PLTMH berupa pemasangan guide vane pada sisi isapan [7], juga telah dilakukan variasi pada nozzle dan sudu turbin [5].

Pembangunan PLTMH juga telah banyak dilakukan diantaranya adalah di Dukuh Pekuluran Kec. Doro Kab. Pekalongan [8], pada industri pengolahan air [9], di Sumbawa [10], PLTMH yang di-hybrid dengan sel surya dan energi angin [11], diperoleh effisiensi maksimum sebesar 66\% [12].

Komponen utama sebuah PLTMH adalah turbin crossflow, pembuatan turbin crossflow ini memerlukan ketelitian serta biaya yang tidak sedikit, sehingga perlu dilakukan analisa waktu dan biaya dalam proses pembuatannya. 
Tentunya dalam memproduksi suatu produk harus mempunyai perhitungan yang matang sebelum melakukan proses produksi, ini bertujuan untuk menghindari kerugian dan untuk mendapatkan profit atau keuntungan dari hasil penjualan produk. Seperti halnya dalam memproduksi turbin Crossflow, dari tahapan-tahapan proses manufaktur turbin dapat diketahui aspek ekonomisnya yaitu biaya dalam memproduksi turbin. Dengan dimensi turbin yang lebih ramping tentunya dapat menekan biaya produksinya.

Umumnya pembuatan turbin jenis crossflow hanya menggunakan satu pancaran dalam menggerakkan roda turbin atau runner. Dalam hal ini, untuk mengetahui perbedaan putaran poros runner turbin pada satu pancaran dengan dua pancaran serta untuk mengetahui biaya pembuatannya dengan dimensi yang lebih ramping, maka akan dilakukan rancang bangun turbin jenis aliran silang pancaran ganda dengan kapasitas mikrohidro yaitu berkisar antara $5 \mathrm{kw}$ hingga $100 \mathrm{kw}$.

Untuk dapat beroperasi dan menghasilkan daya yang diinginkan, sistem kerja Pembangkit Listrik Tenaga Mikrohidro (PLTMH) membutuhkan mekanisme peralatan, debit air dan ketinggian jatuh yang disesuaikan. Hal ini merupakan sebuah sistem konversi energi, sistem mekanis menerima energi dalam bentuk aliran air dan ketinggian jatuh air yang kemudian menyalurkan energi dan mengubahnya menjadi energi mekanik atau energi listrik.

\section{A. Turbin aliran silang (Crossflow)}

Turbin CrossFlow adalah salah satu turbin air dari jenis turbin aksi (impulse turbine). Prinsip kerja turbin ini mula-mula ditemukan oleh seorang insinyur Australia yang bernama A.G.M. Michell pada tahun 1903. Kemudian turbin ini dikembangkan dan dipatenkan di Jerman Barat oleh Prof. Donat Banki sehingga turbin ini diberi nama Turbin Banki atau Turbin Michell-Ossberger' [13].

\section{B. Dasar-dasar rancang bangun turbin}

- Tinggi jatuh air $(\mathrm{H})$ ditetapkan $3 \mathrm{~m}$

- Luas penampang saluran

$\mathrm{A}=1 \times \mathrm{t}$

Dengan $\mathrm{A}=$ luas penampang nosel $\left(\mathrm{m}^{2}\right), \mathrm{L}=$ lebar nosel $(\mathrm{m})$ dan $\mathrm{T}=$ tinggi nosel $(\mathrm{m})$

- Kecepatan absolute air masuk runner [14]

$\mathrm{C}_{1}=\mathrm{Cv} \sqrt{2 \cdot g \cdot H}$

Dengan $\mathrm{C}_{1}=$ kecepatan absolute air masuk runner $(\mathrm{m} / \mathrm{s}), \mathrm{Cv}=$ koefisien kecepatan nosel 0.96 $0.985, \mathrm{~g}=$ percepatan gravitasi $\left(9,81 \mathrm{~m} / \mathrm{s}^{2}\right)$, dan $\mathrm{H}=$ tinggi jatuh $(\mathrm{m})$.

- Debit air [15]

$\mathrm{Q}=\mathrm{A} \times \mathrm{C}_{1}$

Dengan $\mathrm{Q}=$ debit air $\left(\mathrm{m}^{3} / \mathrm{s}\right), \mathrm{A}=$ luas penampang $\left(\mathrm{m}^{2}\right)$ dan $\mathrm{C}_{1}=$ kecepatan absolute air masuk runner $(\mathrm{m} / \mathrm{s})$.

- Daya air [15]

$\mathrm{Pa}=\rho . \mathrm{g} . \mathrm{Q} . \mathrm{H}$

Dengan $\mathrm{Pa}=$ daya air $(\mathrm{kw}), \mathrm{g}=$ percepatan gravitasi $\left(9,81 \mathrm{~m} / \mathrm{s}^{2}\right), \mathrm{Q}=$ debit air $\left(\mathrm{m}^{3} / \mathrm{s}\right), \rho=$ massa jenis air $\left(1000 \mathrm{~kg} / \mathrm{m}^{3}\right)$ dan $\mathrm{H}=$ tinggi jatuh (m).

- Kecepatan spesifik turbin [14]

$$
\mathrm{Ns}=3,65 \times \mathrm{n} \times\left(\frac{\sqrt{\mathrm{Q}}}{\mathrm{H}^{\frac{3}{4}}}\right)
$$

Dengan Ns $=$ kecepatan spesifik $(\mathrm{rpm})$ dan $\mathrm{n}=$ putaran turbin $(\mathrm{rpm})$

- Daya turbin [15]

$\mathrm{Pt}=\rho . \mathrm{g} \cdot \mathrm{Q} \cdot \mathrm{H} . \eta \mathrm{t}$

Dengan $\mathrm{Pt}=$ daya turbin $(\mathrm{kw})$ dan $\eta \mathrm{t}=$ efisiensi turbin $(0.8-0.85$ turbin pelton, $0.8-0.9$ turbin francis, $0.7-0.8$ turbin crossfiow, dan 0.8 - 0.9 untuk turbin propeller Kaplan. 
- Daya generator [14]

$\mathrm{Ng}=$ Pt. $\eta \mathrm{g}$

Dengan $\eta \mathrm{g}=$ faktor daya generator $(0,7-0,9)$ dan $\mathrm{Pt}=$ daya turbin $(\mathrm{kw})$

- Kecepatan tangensial sisi masuk [14]

$\mathrm{U}_{1}=\Phi \times \mathrm{V} \times \operatorname{Cos} \alpha$

Dengan $\Phi=$ speed factor antara $0,44-0,46$ diambil $0,45, \mathrm{U}_{1}=$ kecepatan tangensial sisi masuk $(\mathrm{m} / \mathrm{s}), \operatorname{Cos} \alpha=$ sudut masuk $\left({ }^{\circ}\right)$ dan $\mathrm{C} 1=$ kecepatan air masuk runner $(\mathrm{m} / \mathrm{s})$.

- Diameter runner [14]

Untuk panjang sudu runner ditetapkan $170 \mathrm{~mm}$ untuk dimensi turbin yang lebih ramping.

$\mathrm{L} . \mathrm{D}=2,627 \times \frac{Q}{\sqrt{H}}$

(m).

Dengan $\mathrm{D}=$ diameter Runner $(\mathrm{m}), \mathrm{L}=$ panjang runner $(\mathrm{m}), \mathrm{Q}=$ debit $\left(\mathrm{m}^{3} / \mathrm{s}\right)$ dan $\mathrm{H}=$ tinggi jatuh air

- Lebar lingkaran sudu [15]

$\mathrm{a}=0,17 . \mathrm{D}_{1}$

Dengan a $=$ lebar lingkaran sudu runner $(\mathrm{mm})$ dan $\mathrm{D} 1=$ diameter runner $(\mathrm{mm})$.

- Kelengkungan sudu [13]

$y=0,326 . \mathrm{r}$

Dengan $y=$ kelengkungan sudu dan $r=$ jari-jari diameter runner $(\mathrm{mm})$.

- Putaran runner [13]

$\mathrm{n}=\frac{3,8 \quad \cdot \sqrt{H}}{D 1}$

Dengan $\mathrm{n}=$ putaran turbin $(\mathrm{rpm}), \mathrm{D} 1=$ diameter runner $(\mathrm{mm})$ dan $\mathrm{H}=$ tinggi jatuh air $(\mathrm{m})$

- Diameter dalam runner [13]

$\mathrm{D}_{2}=\mathrm{D}_{1}-2 \mathrm{a}$

Dengan D2 = diameter dalam runner $(\mathrm{m})$

\section{Biaya Manufaktur}

- Biaya bahan langsung

- Biaya tenaga kerja manufaktur langsung, meliputi kompensasi atas seluruh tenaga kerja manufaktur yang dapat ditelusuri ke obyek biaya secara ekonomi dengan cara yang layak berdasarkan hukum sebab akibat.

- Biaya manufaktur tidak langsung, atau biaya overhead manufaktur/pabrik

- Biaya penggunaan listrik selama proses pengerjaan

- Biaya penyusutan peralatan yang disebabkan oleh umur pemakaian

- Biaya penyusutan gedung.

Untuk menghitung Biaya Manufaktur digunakan rumus :

$\mathrm{BM}=\mathrm{BBL}+\mathrm{BTKM}+\mathrm{BMTL}$

Dengan $\mathrm{BM}=$ Biaya Manufaktur, $\mathrm{BBL}=$ Biaya bahan langsung, $\mathrm{BTKM}=$ Biaya tenaga kerja manufaktur dan BMTL = Biaya manufaktur tidak langsung [16].

\section{Waktu pemesinan}

- Persamaan kecepatan potong [17]:

$v=\frac{\pi \cdot d \cdot n}{1}$

- Kecepatan putar [17]:

$\mathrm{n}=\frac{v \cdot 1}{\pi \cdot d}$

- Proses pemotongan [17]

Untuk mengetahui panjang pemesinan :

$1 \mathrm{t}=1 \mathrm{v}+\mathrm{lw}+\mathrm{ln}$ 
Waktu pemotongan benda kerja

$t_{C}=\frac{l_{t}}{v_{f}}=\frac{l_{t}}{n}$

$t_{m}=t_{C}+0.25$ menit/potong

Dengan $\mathrm{d}=$ diameter mata gerinda potong, $v=$ kecepatan potong, $\mathrm{f}=$ gerak makan $(\mathrm{mm} /$ putaran$)$, $\mathrm{n}=$ putaran poros utama $(\mathrm{rpm}), \mathrm{tc}=$ waktu pemotongan $($ menit $), \mathrm{tm}=$ waktu pemesinan (menit), $\mathrm{lt}=$ panjang pemesinan, $\mathrm{lw}=$ langkah pemotongan dan $\mathrm{ln}=$ langkah pengakhiran .

- Proses pembubutan [17]

Untuk mengetahui panjang pemesinan:

$1 \mathrm{t}=\mathrm{lv}+\mathrm{lw}+\ln$

Kecepatan pemakanan :

$\mathrm{Vf}=\mathrm{f} . \mathrm{n}$

Waktu pembubutan:

$t_{C}=\frac{l_{i}}{v}$

$t_{m}=\mathrm{tc}+0,25$

Jumlah pembubutan :

$\mathrm{a}=\frac{d-d}{2} \quad \mathrm{~b}=\frac{a}{\mathrm{~s} \quad \mathrm{~K}} \quad \mathrm{~g}=\frac{b x t}{\mathrm{dxf}}$

Dengan $\mathrm{d} 0=$ diameter awal, $\mathrm{dm}=$ diameter akhir, $v=$ kecepatan potong $(\mathrm{mm} / \mathrm{menit}), \mathrm{f}=$ gerak makan $(\mathrm{mm} /$ putaran$), \mathrm{n}=$ putaran poros utama $(\mathrm{rpm}), \mathrm{Vf}=$ kecepatan pemakanan $(\mathrm{mm} / \mathrm{menit}) \quad$, tc $=$ waktu pemotongan (menit), tm $=$ waktu pemesinan (menit), $\mathrm{Kr}=$ sudut potong utama $\left({ }^{\circ}\right)$ dan $\mathrm{g}=$ jumlah pemakanan

- Proses drilling [17]

Kecepatan makan:

$\mathrm{Vf}=\mathrm{fz} \times \mathrm{n} \times \mathrm{z}$

Panjang permesinan:

$\ln =\frac{\left[\frac{d}{2}\right]}{t_{i} K}$

$1 \mathrm{t}=\mathrm{lv}+\mathrm{lw}+\ln$

waktu pengeboran:

$\mathrm{Tc}=\frac{l_{i}}{V}$

$\mathrm{Tm}=(\mathrm{Tc}+0,25) \times$ jumlah lubang

Dengan $\mathrm{d}=$ diameter mata bor, $v=$ kecepatan potong $(\mathrm{mm} / \mathrm{menit}), \mathrm{f}=$ gerak makan $(\mathrm{mm} /$ putaran $), \mathrm{n}$ $=$ putaran poros utama $(\mathrm{rpm}), \mathrm{tc}=$ waktu pemotongan $($ menit $), \mathrm{tm}=$ waktu pemesinan (menit), $\mathrm{Vf}=$ kecepatan makan dan $\mathrm{z}=$ kecepatan penghasil geram.

- Proses pengelasan [17]

Jumlah elektroda yang dibutuhkan $=\frac{\text { p }}{\text { p }}$

Waktu pengelasan $=$ jumlah elektroda $\mathrm{x}$ lama penggunaan/batang elektroda.

\section{E. Break Even Point (BEP)}

Setelah pengumpulan informasi waktu dan biaya-biaya produksi turbin maka kita dapat mengetahui 3 elemen dari rumus BEP yaitu [18]:

- Biaya tetap (fixed cost)

- Biaya variabel (Variable cost)

- Harga jual turbin

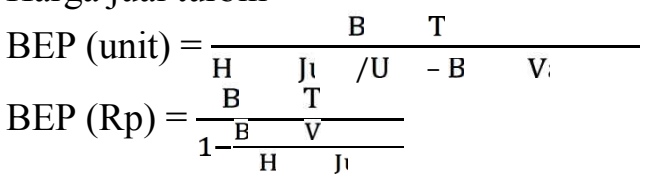




\section{METODE PENELITIAN}

Tempat pembuatan dan perakitan Turbin Crossflow Pancaran Ganda Kapasitas 5-100 kw dilakukan di Bengkel Mekanik Politeknik Negeri Ujung Pandang. Adapun waktu pelaksanaan rancang bangun hingga pembuatan adalah bulan Mei s/d Juli 2014.

- Alat yang digunakan

1. Mesin bubut

2. Mesin CNC milling

3. Mesin pemotong

4. Mesin bending

5. Mesin rol

6. Mesin las

7. Mesin bor

\section{- Bahan yang digunakan}

1. Pipa stom 2 inch

2. Besi profil U

- Komponen turbin yang dibuat:

1. Poros runner dan poros guide vane

2. Piringan runner (disk runner)

3. Sudu-sudu runner

- Komponen turbin yang dibeli:

1. Bearing

2. Mur dan baut
8. Mesin gerinda

9. Ragum

10. Mistar siku

11. Topeng las

12. Penggaris

13. Meteran

14. Tang
3. Plat ST42 dan ST37

4. Baut dan mur
15. Kikir

16. Sikat besi

17. Sarung tangan

18. Palu

19. Kertas gosok

20. Spoit

21. kompressor

5. Besi poros

6. Cat dan tinner

Dalam proses perancangan dilakukan penghitungan dengan menggunakan dasar-dasar perancangan turbin, tujuan perhitungan turbin adalah untuk mendapatkan desain turbin crossflow dua pancaran dengan dimensi turbin yang lebih ramping. Dalam proses manufaktur turbin crossflow pancaran ganda ini juga dilakukan penghitungan waktu serta biaya pembuatan turbin secara teoritis yaitu dengan analisis perhitungan waktu pengerjaan tiap-tiap komponen turbin, setelah didapatkan hasil perhitungan waktu pengerjaan, selanjutnya dapat dilakukan penghitungan biaya untuk mengetahui jumlah biaya produksi turbin Crossflow. Setelah rancang bangun turbin crossflow pancaran ganda telah selesai maka akan dilakukan pengujian pada turbin, pengujian ini dilakukan untuk mengetahui perbedaan putaran yang terjadi pada poros runner turbin.pada penggunaan satu pancaran dengan dua pancaran.

\section{HASIL DAN PEMBAHASAN}

Dalam perancangan pertama-tama dilakukan adalah menghitung dimensi turbin. Selanjutnya hasil perhitungan dibuat dalam desain dan gambar kerja dari dimensi-dimensi hasil penghitungan, aplikasi gambar yang digunakan adalah CAD-CAM dan Auto Desk Inventor. Beberapa komponen dikerjakan dengan menggunakan mesin CNC untuk mendapatkan dimensi komponen yang presisi seperti pembuatan sudu pada komponen disk runner. Proses pembuatan ini menghasilkan 2 buah runner yang dibuat dengan bahan dan dimensi sama namun jumlah sudunya berbeda yaitu 25 sudu dan 28 sudu.

Dalam rancang bangun turbin untuk proses pemesinan ditetapkan asumsi-asumsi waktu sebelum dan sesudah proses pemesinan benda kerja. Setiap waktu proses pengerjaan bahan dijumlahkan dengan asumsi-asumsi dan menjadi waktu pengerjaan setiap proses pemesinan. Adapun waktu yang dibutuhkan dalam proses permesinan dapat dilihat pada tabel 1 . 
Tabel 1. Jumlah total waktu pemesinan

\begin{tabular}{|c|l|l|}
\hline No. & Proses pemesinan & \multicolumn{1}{|c|}{ Jumlah waktu } \\
\hline 1. & Proses gerinda & 1 jam 45 menit \\
\hline 2. & Proses bending sudu & 1 jam 4 menit \\
\hline 3. & Proses bubut & 9 jam 38 menit \\
\hline 4. & Proses drilling & 1 jam 8 menit \\
\hline 5. & Proses pengelasan & 6 jam 7 menit \\
\hline 6. & CNC & 14 jam 13 menit \\
\hline \multicolumn{2}{|c|}{ Jumlah } & 33 jam 55 menit \\
\hline
\end{tabular}

Analisa pada proses pemesinan dilakukan untuk mengetahui biaya pembuatan turbin Crossflow Pancaran Ganda Kapasitas 5-100 kw. Biaya-biaya itu berupa biaya tenaga kerja yang dapat dilihat pada tabel 2, biaya lainnya adalah biaya bahan, biaya tidak langsung dan biaya manufaktur yang dapat dilihat pada tabel 3, serta dalam analisa biaya juga dilakukan perhitungan biaya tetap dan biaya variabel yang dapat dilihat pada tabel 4.

Biaya yang dihitung pada tabel 2, tabel 3 dan tabel 4 disesuaikan dengan biaya yang berlaku saat pelaksanaan pembuatan turbin Crossflow Pancaran Ganda Kapasitas 5-100 kw

Tabel 2. Biaya tenaga kerja

\begin{tabular}{|c|c|c|c|c|c|}
\hline No. & $\begin{array}{c}\text { Jenis } \\
\text { Pengerjaan }\end{array}$ & $\begin{array}{c}\text { Waktu } \\
\text { pengerjaan }\end{array}$ & Upah/bulan & Upah/jam & $\begin{array}{c}\text { Upah } \\
\text { pengerjaan }\end{array}$ \\
\hline 1. & Gerinda & 1 jam 45 menit & \multirow{5}{*}{ Rp 1.500 .000} & \multirow{6}{*}{$\operatorname{Rp} 8.670,52$} & $\operatorname{Rp} 12.572,25$ \\
\hline 2. & Bubut & 9 jam 38 menit & & & $\operatorname{Rp} 81.329,47$ \\
\hline 3. & Drilling & 1 jam 8 menit & & & Rp 15.606,93 \\
\hline 4. & Las & 6 jam 7 menit & & & Rp 47.080,92 \\
\hline 5. & $\mathrm{CNC}$ & 14 jam 13 menit & & & Rp 200.000 \\
\hline \multicolumn{4}{|c|}{ Jumlah total biaya tenaga kerja } & & Rp 356.589,57 \\
\hline
\end{tabular}

Tabel 3. Biaya bahan, biaya tidak langsung dan biaya manufaktur

\begin{tabular}{|c|c|c|c|c|}
\hline No. & Biaya & Rincian & Harga & Jumlah \\
\hline \multirow{2}{*}{1.} & \multirow{2}{*}{ Biaya bahan } & Bahan langsung & $\mathrm{Rp} \quad 3.745 .500$ & \multirow[t]{2}{*}{-1} \\
\hline & & Bahan tidak langsung & Rp $\quad 2.240 .000$ & \\
\hline \multirow{5}{*}{2.} & \multirow{5}{*}{$\begin{array}{c}\text { Biaya tidak } \\
\text { langsung }\end{array}$} & Biaya bahan tidak langsung & Rp 2.240 .000 & \multirow{5}{*}{ Rp 11.553.531 } \\
\hline & & Biaya listrik/bulan & 171.406 & \\
\hline & & Biaya penyusutan mesin/bulan & Rp 9.099 .615 & \\
\hline & & Biaya penyusutan peralatan/bulan & 7.620 & \\
\hline & & Biaya penyusutan gedung/bulan & 34.890 & \\
\hline \multirow{3}{*}{3.} & \multirow{3}{*}{$\begin{array}{l}\text { Biaya } \\
\text { manufaktur }\end{array}$} & Biaya bahan langsung & Rp 3.745 .500 & \multirow{3}{*}{ Rp 15.661 .863} \\
\hline & & Biaya tenaga kerja & 362.832 & \\
\hline & & Biaya tidak langsung & Rp 11.553 .531 & \\
\hline
\end{tabular}

Tabel 4. Biaya tetap dan biaya variabel

\begin{tabular}{|c|c|l|l|c|}
\hline No. & Biaya & \multicolumn{1}{|c|}{ Rincian } & \multicolumn{1}{|c|}{ Harga } & Jumlah \\
\hline \multirow{3}{*}{1.} & \multirow{3}{*}{ Biaya tetap } & Biaya listrik & $\mathrm{Rp} 171.406$ & \multirow{3}{*}{$\mathrm{Rp} 10.011 .331$} \\
\cline { 3 - 4 } & & Biaya sewa gedung & $\mathrm{Rp} 697.800$ & \\
\cline { 3 - 4 } & & Biaya penyusutan gedung & $\mathrm{Rp} 34.890$ & \\
\hline
\end{tabular}




\begin{tabular}{|l|l|l|l|l|}
\hline & & Biaya penyusutan mesin & $\mathrm{Rp} \mathrm{9.099.615}$ & \\
\cline { 3 - 4 } & & Biaya penyusutan peralatan & $\mathrm{Rp} \mathrm{7.620}$ & \\
\hline \multirow{3}{*}{2.} & \multirow{3}{*}{ Biaya variabel } & Biaya bahan langsung & $\mathrm{Rp} \mathrm{3.745.000}$ & \multirow{3}{*}{$\mathrm{Rp} 6.347 .832$} \\
\cline { 3 - 4 } & Biaya tenaga kerja & $\mathrm{Rp} \mathrm{362.832}$ & \\
\cline { 3 - 4 } & & Biaya bahan tidak langsung & $\mathrm{Rp} \mathrm{2.240.000}$ & \\
\hline
\end{tabular}

\section{- Break Event Point}

Titik impas atau BEP pembuatan turbin crossflow pancaran ganda ini akan tercapai saat produk terjual sebanyak 3 unit/bulan atau pada saat penghasilan mencapai Rp. 27.365.244,-. Dilihat dari hasil perhitungan, profit telah didapatkan dari penjualan sebanyak 3 unit (harga jual perunit adalah Rp. 10.000.000), namun untuk mendapatkan profit atau keuntungan lebih maka kita harus mampu menjual produk lebih dari 3 unit dalam satu bulan.

\section{- Pengujian turbin}

Dari pengujian yang telah dilakukan dengan tinggi jatuh air $(\mathrm{H})=3 \mathrm{~m}$ dan $\operatorname{debit}(\mathrm{Q})=0,23 \mathrm{~m}^{3} /$ detik didapatkan data putaran poros runner pada tabel berikut:

Tabel 5. Data hasil pengujian

\begin{tabular}{|c|c|c|c|}
\hline No & Nosel & Bukaan Katup & Putaran (rpm) \\
\hline \multirow{3}{*}{1.} & \multirow{3}{*}{1 nosel } & Kecil $\left(30^{\circ}\right)$ & 383 \\
\cline { 3 - 4 } & & Sedang $\left(15^{\circ}\right)$ & 372 \\
\hline & & besar $\left(0^{\circ}\right)$ & 365,4 \\
\hline \multirow{2}{*}{2.} & \multirow{3}{*}{2 nosel } & Kecil $\left(30^{\circ}\right)$ & 374 \\
\cline { 3 - 4 } & & Sedang $\left(15^{\circ}\right)$ & 370 \\
\cline { 3 - 4 } & & besar $\left(0^{\circ}\right)$ & 371 \\
\hline
\end{tabular}
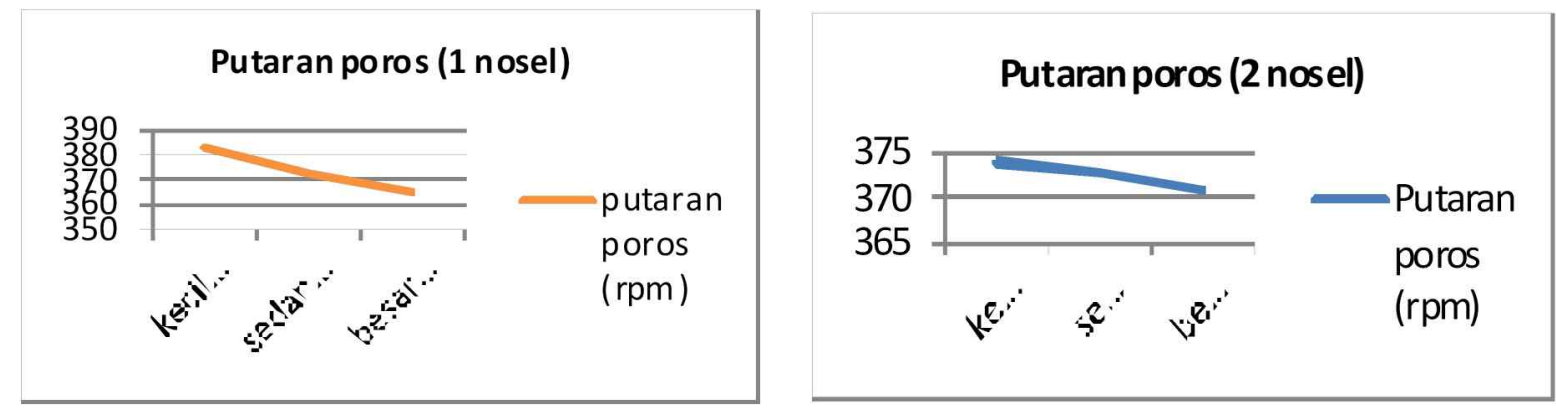

Gambar 1. Hasil uji putaran poros 1 dan 2 nosel

Dari data hasil pengujian putaran poros turbin didapatkan kecepatan putar tertinggi yaitu pada bukaan satu katub dengan sudut masuk $30^{\circ}$ yaitu $383 \mathrm{rpm}$ dan kecepatan putar poros terendah pada bukaan satu katub penuh yaitu 365,4 rpm. 


\section{KESIMPULAN}

Berdasarkan hasil dan pembahasan yang telah dilakukan dalam penelitian ini, maka dapat ditarik kesimpulan bahwa:

1. Total waktu pemesinan Turbin Crossflow Pancaran Ganda kapasitas $5-100 \mathrm{kw}$ adalah 33 jam 55 menit. Berdasarkan waktu pemesinan turbin tersebut, maka didapatkan biaya manufaktur turbin yaitu sebesar $\mathrm{Rp}$ 15.661.863 dan Break Event Point turbin tercapai pada saat penghasilan mencapai Rp27.412.022, yaitu saat turbin terjual sebanyak 3 unit/bulan dengan harga $\mathrm{Rp}$. 10.000.000,- perunit.

2. Pembuatan runner dengan bahan ST42, diameter $200 \mathrm{~mm}$,dan jumlah sudu sebanyak 28 sudu. Luasan saluran masuk turbin $324 \mathrm{~cm}^{2}(18 \times 18 \mathrm{~cm})$ dan dimensi turbin Crossflow $(\mathrm{p} \times 1 \times \mathrm{x})=$ $48,9 \mathrm{~cm} \times 29 \mathrm{~cm} \times 37 \mathrm{~cm}$. Dalam pengujian yang telah dilakukan didapatkan data putaran poros runner pada satu sudu berkisar 365,4 s/d $383 \mathrm{rpm}$ dan pada dua sudu berkisar $370 \mathrm{~s} / \mathrm{d} 375 \mathrm{rpm}$.

\section{DAFTAR PUSTAKA}

[1] Napitupulu F.H. 2008. Potensi Air Terjun Sebagai Pembangkit Listrik Tenaga Minihidro (PLTMH) di Sumatera Utara. Pidato Pengukuhan Jabatan Guru Besar Tetap dalam Bidang Ilmu Mekanika Fluida pada Fakultas Teknik, diucapkan di hadapan Rapat Terbuka Universitas Sumatera Utara.

[2] Kurniawan B. 2007. Mengapa Mikrohidro. Seminar nasional teknologi (SNT 2007) ISSN : 1978-9777, Yogyakarta.

[3] Winardi, Harwin Saptodi, 2004. Pengaruh Jumlah Sudu Jalan Terhadap Unjuk Kerja Turbin Aliran Silang, TEKNOSAINS April 2004. Hal .230-250

[4] Yus Widarko. dkk, 2004, The Efects Of Opening Variation Of Guide Van On The Effeciency Of Cross Flow Turbine, Program Studi Magister Sistim Teknik Mikro Hidro, UGM.

[5] Yong D.C., dkk. 2008. Performance and Internal Flow Characteristics of a Cross-Flow Hydro Turbine by the Shapes of Nozzle and Runner Blade. Jurnal of Fluid Science and Technology. Korea Maritime University. Vol.3, No3, 2008.

[6] Jusuf Haurissa, Rudi Soenoko, 2010, Performance and Flow Characteristics Lattitude With Addition in Nozzle, Turbine Blades Second Level. IJAR Journal Economics And Engineering no. 4, Page: $30-32$. Azerbaijan

[7] Junichiro F. dan Rei N. 2005. Performance and Internal Flow of Cross-Flow Fan with Inlet Guide Vane. JMSE International Journal series B, vol. 48, No. 4

[8] Sudargana dkk. 2005. Studi Kelayakan dan Prancangan Pembangkit Listrik Tenaga Mikrohidro di Dukuh Pekuluran Kec. Doro Kab. Pekalongan. Jurnal ROTASI Volume 7, Nomor 2, Halaman $1-5$.

[9] Theophilus Gaius dan obaseki. 2010. Hydropower opportunities in the water industry. International Journal of Environmental Sciences Volume 1, No 3, Hal 392-402. ISSN 0976 4402.

[10] Abdul A.H. dan Lily M. 2011. Design of Micro Hydro Electrical Power at Brang Rea River In West Sumbawa of Indonesia. Journal of Applied Technology in Environmental Sanitation, Volume 1, Number 2, Page: 177-183. ISSN 2088-3218

[11] Deepak K.L., dkk. 2011. Optimization of PV/Wind/Micro-Hydro/Diesel Hybrid Power System in HOMER for the Study Area. International Journal on Electrical Engineering and Informatics $\square$ Volume 3, Number 3, Page 307-325.

[12] Javet C. dkk. 2010. Design Of A Cross Flow Turbine For Micro Hydro Power Application. Proceeding of the ASME Power Comfrence Power 2010, Cicago USA July, 13-15 2010. 
[13] Haimerl, LA. “The crossflow turbine' water power. Jerman Barat. 1960.

[14] Purwanto, Agung Ari, dan Jumaedi. 2013. Rancang Bangun Turbin Cross Flow Pembangkit Listrik Tenaga Mikrohidro dengan Variasi Debit dan Head. Laporan Skripsi. Jurusan Teknik Mesin Politeknik Negeri Ujung Pandang. Makassar.

[15] Halim, S. 2010. Karakteristik dan Effisiensi Turbin Cross Flow Untuk Pembangkit Listrik Tenaga Mikro Hydro (Uji Laboratorium). Fakultas Teknik Universitas Sumatera Utara. Medan.

[16] Hery, S.E., M.SI. 2012. Cara Mudah Memahami Akuntansi: Intisari Konsep Dasar Akuntansi. Penerbit: Prenada, Jakarta.

[17] Wicaksono, A. R. 2010. Analisa Proses Permesinan Dan Biaya Produksi Pada Mesin Hot Press Berbasis PLC. Tugas Akhir. Jurusan Teknik Mesin Fakultas Teknologi Industri Institut Teknologi Sepuluh Nopember. Surabaya.

[18] Mulyadi, M. dkk. 2013. Rancang Bangun Turbin Cross Flow Kapasitas 2500 watt dan Analisis Biaya Produksinya. Skripsi. Jurusan Teknik Mesin Politeknik Negeri Ujung Pandang. Makassar. 